ISSN 0819-2642

ISBN 0734025904

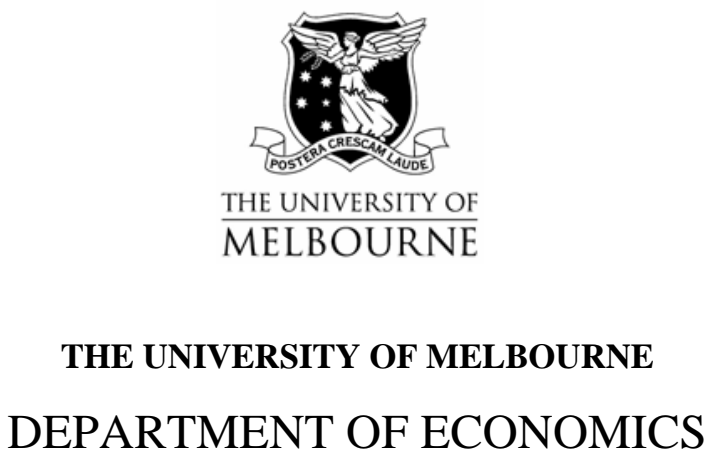

RESEARCH PAPER NUMBER 934

MARCH 2005

FROM MANUSCRIPT TO PUBLICATION:

A BRIEF GUIDE FOR ECONOMISTS

by

John Creedy

Department of Economics

The University of Melbourne

Melbourne Victoria 3010

Australia. 


\title{
From Manuscript to Publication: A Brief Guide For Economists*
}

\author{
John Creedy
}

\begin{abstract}
The aim of this paper is to give a short description of the nature of books and journals, their respective editors, and the difficult process and proprieties involved in publishing papers. It describes some of the main features of the publication process, so that readers may be in a better position to make judgements about published work and writers may be, to some extent at least, prepared to face the difficulties that inevitably lie in their path. Emphasis is given to the need to deal with rejections and the often substantial revisions requested by editors. While some of the features of publishing are common to all disciplines, this paper is specifically intended for economists.
\end{abstract}

*This paper was written in response to several requests from colleagues and graduate students. It can be regarded as a sequel to my paper on starting research and writing research reports; see Creedy (2001), substantially revised and extended in Creedy (2002). I should like to thank Veronica Jacobsen for encouragement and helpful discussions, and Siobhan Austen, Harry Bloch, Mark Casson, Robert Dixon, Nisvan Erkal, John Fender, Norman Gemmell, Ross Guest, Guyonne Kalb, Ingrid Linsley, and Denis O'Brien for comments on an earlier version. However, as these people were not referees, I have had the luxury of being selective in following their comments. 


\section{Introduction}

It is perhaps tempting to believe that the hard work involved in producing research ends with the completion of a manuscript. In reality, the path from manuscript to publication can present many hazards not met during the research itself, and involves a new and quite different type of learning process. The various stages of the publication process are designed to act as a selection device, or filter, and to improve the quality of the final product itself. Without these features it is likely that many more articles and books would contain serious errors or material that is unclear or directed to a narrower audience than necessary. Of course, where subjective judgements are involved concerning the value of work, it is possible that the same features sometimes prevent useful material from being published, or being published in an appropriate form. No filter can be perfect.

The aim of this paper is therefore briefly to indicate some of the main features of the publication process, so that readers may be in a better position to make judgements about published work and writers may be, to some extent at least, prepared to face the difficulties that inevitably lie in their path. ${ }^{1}$ While some of the features of publishing are common to all disciplines, there are important differences. This paper is specifically intended for economists.

First, comparisons between books and journals are made in section 2, concentrating on the aims of, and constraints imposed on, editors which influence their behaviour. Section 3 discusses the growth in the number of journals. These first two sections provide a broader context for discussing appropriate publication strategies for authors, as well as indicating to readers why the styles of books and journals are so different and why, for example, journal articles are usually so terse. The next two sections concentrate on the process of a journal article from its submission to eventual acceptance and publication. Section 4 discusses submission, the way to deal with referees' reports and the approach to revis-

\footnotetext{
${ }^{1}$ Much has been written about the many facets of the publication process. For a collection of papers on publishing in economics, see Gans (2000). Regarding book publishing, the famous description and memoirs of Unwin $(1926,1960)$ are still worth reading, despite the revolutions in printing technology and the structure of the industry that have since taken place. For a collection of publishing anecdotes, see Huggett (1986).
} 
ing papers. Section 5 briefly concerns the role of sub-editors in the production process, and the importance of checking proofs carefully. Concluding comments are in section 6 .

\section{Books and Journals}

The major forms of publication for research work are books and refereed journals. ${ }^{2}$ Without doubt the most important people, at least from the point of view of authors, are the editors. Hence a useful way to describe the main characteristics of these forms of publication is to begin by contrasting the nature of the editors themselves, and their quite different modes of behaviour and editorial policies. When discussing books here, the term editor is used instead of the more cumbersome 'commissioning editor'. ${ }^{3}$

\subsection{The Aims of Editors}

It is first necessary to stress that the main aims of book and journal editors are quite different. Put baldly, journal editors are looking for articles that have something new and worthwhile to say while book editors are looking for something that will sell. Originality is the primary requirement of a journal article, the success of which is judged by the number of subsequent citations and the enhanced reputation of the journal and of course the author. ${ }^{4}$

The first question of book editors is not 'is this original?' but 'will this sell?' Of course, editors also like to have books that will enhance the quality of their lists, and perhaps attract other authors, but the market test is the crucial one. The lack of concern for originality is obvious in the case of textbooks, though of

\footnotetext{
${ }^{2}$ Other forms include departmental working papers, pamphlets, reports and other nonrefereed forms, along with the more recently introduced form of 'on-line' publishing. For discussion of the latter possibilities, many of which have since been put in practice, see Goffe and Parks (1997).

${ }^{3}$ At one time, editors played a significant editorial role, particularly with non-academic works. A distinction also needs to be made regarding 'contributed' volumes (including festscrifts and conference volumes), which are not discussed here.

${ }^{4}$ Journals publish literature reviews, but these require a fresh perspective and the synthesis of often disparate threads, along with the exercise of judgements regarding methods and directions of research.
} 
course a fresh style of exposition and perspective play a significant role. However, research volumes (usually referred to as monographs) may include material that the author has previously published in journal form. ${ }^{5}$ Indeed, in view of changes to the academic reward system which have substantially reduced the incentive to publish books, it is less likely that authors are prepared to publish original material only in a book. But the results of a substantial research programme, having a unifying theme, can often usefully be revised and brought together in a single volume after they have been published separately in a series of journal papers. It is also possible to include explanatory details and further discussion that could not be published in journal form. Such books are particularly valuable for later generations of researchers who are looking for an overview of a particular subject.

\subsection{Editors Compared}

Many of the behavioural differences between journal and book editors become clearer once the motivating factors, and constraints, are recognised. First, journal editors are not paid employees, though some editors may receive a small honorarium. Many journal editors are appointed by some type of society, in much the same way that any other office bearer is appointed. Importantly, this means that there are no real sanctions regarding performance: it can be extremely difficult to remove a journal editor, however poor the performance or numerous the complaints made.

Journal editors are not selected according to their knowledge of the printing and publishing business, or even their administrative abilities. Many therefore know little, and care even less, about those aspects. If journal editors face no sanctions, have little knowledge of the technical and commercial aspects of publishing, and have no financial incentives regarding outcomes, it is inevitable that factors such as power, influence and ego play a role, thereby damaging the selection process. Many editors nevertheless do provide a valued and disinterested

\footnotetext{
${ }^{5}$ This may require copyright clearance, but most copyright assignment contracts used by journals explicitly allow for such republication by the author.
} 
service to the scholarly community. It is perhaps surprising how well the system generally works, though there are huge variations in editorial standards.

Book editors are, in contrast, paid professionals whose remuneration depends on the sales of books they commission. There is thus a clear market sanction. There is indeed much mobility within the industry, as successful editors are 'headhunted'. 6 Commissioning editors typically know the publishing business well from many points of view, having often 'worked their way' though a number of departments.

The behaviour patterns of the different editors are therefore, not surprisingly, quite distinct. Journal editors simply wait for submissions to arrive. ${ }^{7}$ With limited space available, emphasis is given to the selection process involving the rejection of a large proportion of submitted papers. ${ }^{8}$ Editors are generally, though not always, well known and often highly regarded academics. They are confident of their own ability to make judgements regarding the quality of papers submitted, though an important role is played by referees, as discussed below. Furthermore, an editor may consult an editorial board before making a final decision, but this is not common. Journal editors have little, and merely distant, contact with authors. Given the search for original high-quality papers, past reputations of authors typically count for little. ${ }^{9}$

Book editors, on the other hand, must actively solicit manuscripts and proposals from potential authors. ${ }^{10}$ They welcome submissions, but in approaching a publisher it is usually necessary to complete a detailed proposal form. Authors should never simply post a manuscript to a publishing house, but should take the trouble to find the name of the editor. Information for authors can usually be obtained from book catalogues and internet sites, from which proposal forms

\footnotetext{
${ }^{6}$ This, combined with frequent take-overs, can have negative effects for individuals authors - when there is no one to promote their book in the organisation.

${ }^{7}$ However, editors of new journals need to make an effort to get submissions, for which they often use 'special issues'.

${ }^{8}$ Rejection rates vary substantially among disciplines but are very high in economics. At the other extreme, law journals are largely edited by students, so there are few rejections. Publication and processing delays also vary substantially.

${ }^{9}$ Furthermore, a double blind review process is now sometimes used; however, the identity of an author can usually easily be guessed.

${ }^{10}$ Certain university presses are less energetic in this regard.
} 
can also be obtained.

Unlike journal editors who give much of their attention to rejecting papers, book editors place most emphasis on encouraging authors, with the aim of increasing their lists. They make themselves known to academics by visiting departments and attending conferences. They are not, and make no claims to be, experts in the field. However, they make it their business to find out about reputations (including not only academic qualities, but reliability and ease of dealing with authors). Referees of book proposals, and publishers' readers of finished manuscripts, are paid for their services and are encouraged to be constructive.

Book editors often establish long term relationships with authors. ${ }^{11}$ They are invariably pleasant, congenial people. Their aim is to help authors to produce books which will sell. They are not judgemental in the way that journal editors are, and are not threatened by others or affected by professional prejudices or jealousies of the kind that may sometimes influence decisions of journal referees and editors.

\section{Journals: Demand and Supply}

The most cursory glance at academic journals reveals a huge increase in the number of journals, with most of the newer journals in recent years being 'field' journals concerned with reasonably well-defined areas within the discipline. In addition, the majority of journals are published, marketed and distributed by established publishing houses. ${ }^{12}$

The demand side of journals includes both the demand by readers (fellow professionals and students) and the demand for publishing outlets by researchers. The most obvious factor has been the growth of the economics profession itself, associated with the large increase in university numbers, and the associated growth of university libraries with funding to purchase journals. The stimulus provided by the growth of universities has also been enhanced by the "publish or

\footnotetext{
${ }^{11}$ For samples of correspondence, in (mostly) non-economics publishing, see Nowell-Smith (1967), Wheelock (1950) and Roberts (1966).

${ }^{12}$ Indeed, some publishers such as Blackwells have concentrated so much on journals that they now form the largest part of the business.
} 
perish' imperative that exists. Academic appointments, reputation and promotion depend largely on journal publications.

The 'mainstream' journals, such as the American Economic Review and the Economic Journal which date from the end of the nineteenth century, are associated with the time when economists were becoming conscious of their professional status, distinct from other social or political studies, and felt the need to provide a new form of publication outlet for their work. ${ }^{13}$ In the earlier years, these journals also published work by individuals who were not attached to university economics departments.

The large growth in the number of academic economists has also led to a considerable increase in the extent of specialisation. This has in turn given rise to a demand for more 'field journal's dealing with specific areas or research. The increased professionalisation of the subject was initially partly associated with the introduction of new analytical techniques. Initially, some economists found it difficult to publish their work in the existing journals and so launched their own journals, often connected with the formation of their own societies. Obvious examples of this type include the Review of Economic Studies and Econometrica, dating from the 1930s. In more recent years there are too many in this category to list.

Some journals are described as 'house journals'. These are not necessarily associated with specialist fields but are started by particular departments, or research institutes, eager to enhance their own publications. ${ }^{14}$ However, they usually also accept submissions from researchers elsewhere. Examples of longestablished house journals include Journal of Political Economy (Chicago), Economica (London School of Economics), Oxford Economic Papers (Oxford), the

\footnotetext{
${ }^{13}$ The examples given above are of journals started by national associations, to which many economists working in the countries are expected to belong, and which organise annual conferences. Other examples include the Canadian Journal of Economics, the Scottish Journal of Political Economy and the Economic Record. There are also regional organisations, as in the case of the Southern Economic Journal.

${ }^{14}$ Examples include the journals produced by organisations such as the National Institute of Economic and Social Research (UK), the Melbourne Institute of Applied Economic and Social Research (Australia), the Institute For Fiscal Studies (UK), the Brookings Institution, and the International Monetary Fund.
} 
Manchester School (Manchester), and Quarterly Journal of Economics (Harvard). Their editors are always drawn from within the particular department, and not surprisingly the quality of articles varies substantially even where the average quality of editors and papers is high.

On the supply side, publishers are attracted by the cash flow advantages of journals. Unlike books, where the uncertain returns accrue long after the expenses of paper, printing, binding, marketing and distribution have been incurred, journal subscriptions for a year ahead arrive at the beginning of the year. Not only are editors not paid, as mentioned above, but contributors receive no fee. Indeed some (though few) journals charge authors a cost per page, and many charge authors submission fees and impose costs for off-prints. ${ }^{15}$ In recent years, further costs have been shifted to authors, who are now expected to provide camera-ready copy of diagrams, along with digital copies of papers laid out in an approximation to the journal's 'house style'.

Where a publisher is responsible for several journals, there are economies of scale regarding marketing and distribution. Furthermore, journals can provide a regular flow of work for a publisher's production department and (sub-contracted) printers, which fill in any slack time. Journals do not take priority but allow some flexibility in scheduling work. Unlike books, where unsold copies are eventually pulped or remaindered, it is known from subscriptions approximately how many copies to print.

The above features also explain why journals have limited space and little flexibility. The subscription cost, and the agreement with the publisher, involves an explicit page limit per issue. It is important for each journal to have its own house style, involving page and font size, spacing, margins and other layout characteristics, along with paper quality and colour. These features cannot be varied to accommodate more or longer papers. With books, there is much more flexibility and of course each book is priced separately. ${ }^{16}$

\footnotetext{
${ }^{15}$ Typically a publisher has a contract with, say, an economics society or research institute. These vary, but usually involve the payment of a minimum fixed amount by the publisher at the end of the year. The burden of subediting and layout is sometimes borne (in terms of organisation and cost) by the society running the journal, but more often by the publisher.

${ }^{16}$ Nevertheless a book contract will specify the (approximate) number of pages, and authors
} 


\section{Publishing in Journals}

This section concentrates on the special problems arising from the process of getting an article published in a journal. The important first stage for the author, the journal choice and submission, is discussed in subsection 4.1. There are really only two broad types of response from editors, and these are discussed here. Subsection 4.2 considers the response to a rejection letter. The much more positive response - though it may not always seem so at the time - is the letter inviting revision and resubmission. This is discussed in subsection 4.3.

The broader subject of the various strategic aspects of writing and journal publishing are not discussed here. ${ }^{17}$ However, it is important not to be excessively negative about previous treatments of the topic or to emphasise originality by being provocative. Indeed, the very people being criticised may well be referees. Also, even the disinterested reader finds emphasis on negative points irritating, which may lead to a crucial loss of sympathy. ${ }^{18}$

Furthermore, where the origins of a paper are in a thesis, substantial revisions are usually required before it is ready to be submitted to a journal. It must give all the indications of being a mature piece of work. Signs of immaturity, which are often evident in work taken from theses, include overlong and meandering introductions and conclusions, too many non-relevant citations, too many vague allusions, excessive claims for originality and policy relevance, long dense footnotes, and gratuitous criticisms of earlier work.

\subsection{Submission}

One rule regarding journal submissions in economics stands out above all other requirements. The single most important propriety for authors to recognise is that a paper can be sent to only one journal at a time. The submission of a research paper contrasts with a book manuscript in this respect. Indeed, not

should endeavour to keep to this agreed length. Commissioning editors will have a view about the appropriate length and price for the market.

${ }^{17}$ For discussion of these issues, see Fischer and Lawrence (1997).

${ }^{18}$ A similar point was made by Hamermesh (1992), who also stressed the importance of not 'playing games' regarding acknowledgements and citations. 
only can a book manuscript be sent to several publishers (commissioning editors) simultaneously, but proposals - rather than the finished product - can be sent. In view of the much greater investment of time involved in writing a book, many authors prefer to obtain a contract, based on a proposal and perhaps some sample material. ${ }^{19}$

It should go without saying that before sending a paper to a journal, always ensure that it really is ready. Too often, editors receive papers that immediately convey - from their initial appearance or the opening paragraphs or state of tables, figures and references - all the wrong signals. Crucially, authors should try to obtain comments from sympathetic colleagues. ${ }^{20}$ They do not need to be experts in the area of the paper, but need to be willing to devote the time needed to give constructive advice. They can also advise against making extensive revisions to a draft that may not actually be required. University departments are much less collegial than they once were, and it is more difficult to get feedback from colleagues. But there is no doubt that those departments having some kind of editorial process for the release of their working papers enhance the publication chances of papers. ${ }^{21}$

The first things the editor looks at are the title and the abstract, so it is important to make these as clear as possible. Despite this, many journal articles now often have highly allusive titles that give little indication of the subject of the paper, except perhaps to a small clique. ${ }^{22}$ It is worth keeping later generations of readers in mind, for whom the allusions may mean nothing.

\footnotetext{
${ }^{19} \mathrm{~A}$ book proposal needs to establish the existence of a likely market. The publisher takes a risk regarding the final quality, which is one reason why reputation is much more important in this context. Authors should be aware that contracts contain several clauses allowing the publisher to withdraw.

${ }^{20}$ As this paper is about the publication process, this is not the place to discuss the relative merits of journals. However, early researchers would usually benefit from advice about the chances of publishing their paper in alternative journals, and the likely waiting times involved.

${ }^{21}$ Those who have made useful comments should of course be acknowleged but, in the words of Hamermesh (1992, p. 171), 'avoid the usual callow exculpation of them'. Never add acknowledgements to people who have not read the paper.

${ }^{22}$ In view of the market imperative, readers (including reviewers) of books should be aware that a publisher's marketing department often influences the title of a book. It is easy to discern fashions in titles. Non-academic histories and biographies now often refer to a minor feature of their subject. For example, a recent example following Greene's Lord Rochester's Monkey is Lady Gregory's Toothbrush.
} 
The journal should be selected carefully. Never send a paper to a journal without first looking through some recent issues to check if there are earlier related articles and whether it covers suitable fields and methods. Journals often provide a policy statement in their web site. Many papers are rejected without even being sent to referees because the editor immediately considers them unsuitable for the particular journal. It is also useful for inexperienced authors to seek advice on how well a prospective journal is edited. There are regrettably always some journals that are best avoided, unless one wishes to wait two or more years for a three-line rejection.

Each journal has its own submission requirements, which need to be checked carefully. Submission is now often made easier by the ability to send pdf files as email attachments. When sending the paper, a brief formal covering letter of a couple of sentences is sufficient. The editor does not need to be told that the sender is looking forward to his or her response.

One of the first things authors need to develop is patience. In economics, the refereeing process can usually be expected to take a long time. The time between submission of the paper and a first response from the editor has without doubt increased in recent years: as an approximation, the median time is getting close to one year. Many authors would be horrified to discover how long their papers sit on an editor's desk before being sent to referees. Then when referees receive papers, they cannot be expected to take high priority when all academics are under great pressure to produce their own work. Almost the only incentive facing referees is a vague feeling that they are part of a community, and cannot expect to have their own work refereed seriously if they are not also prepared to contribute to the system. ${ }^{23}$ Referees are are seldom given a financial reward for their work and, when they are paid, the amount is trivial.

\footnotetext{
${ }^{23}$ Hamermesh (1994) reported the results of a survey of journals regarding choice of, and behaviour by, referees. The summary statistics regarding turnaround times would almost certainly differ from current experience.
} 


\section{$4.2 \quad$ Rejection}

The most frequent response from a journal editor is an unequivocal rejection - it is worth keeping this in mind when dealing with a rejection letter. Such rejections are much more common in economics than in most other disciplines. Indeed, many famous economics articles have been rejected by numerous journals. ${ }^{24}$ The most-published authors usually also necessarily have the most rejections along the way. The refereeing process introduces a substantial element of luck. Every author can easily think of some of their better papers which they have had great difficulty publishing, while some weaker papers have experienced few hurdles.

In dealing with rejections, it is necessary to find a balance between selfconfidence, which is a fundamental pre-requisite for any kind of research activity, and a willingness to learn from criticism. It is necessary, though never easy, to develop a thick skin. ${ }^{25}$

One point may take some time to appreciate. Despite the sometimes abusive and unkind comments, or frequently lazy and easy criticisms produced by referees, remember that it is not personal. A great deal could be written on the culture of negativity that has developed within the economics profession and the damage it has caused. Referees automatically look for things to criticise. But it is worth remembering that, after all, referees are human. There may be aspects of the paper that they find irritating, they are often very busy indeed and cannot spend the time to struggle with something that is unclear, they have their own little 'hobby horses', or they may simply have had a bad day. And in writing their reports they are of course protected by anonymity.

Also, keep in mind that after receiving a rejection, and possibly unpleasant referees' reports, it is not the last chance: to borrow the often-quoted line of a famous film, 'tomorrow is another day'. The paper can be revised, there are other journals and the criticism is, after all, not public. ${ }^{26}$ In this last aspect, a contrast

\footnotetext{
${ }^{24}$ Many examples have been collected by Gans and Shephard (1994), and Shephard (1995).

${ }^{25}$ It is usually not difficult to think of those who need to develop a thinner skin, but this type is fortunately observed less frequently.

${ }^{26}$ However, at least one author has circulated a working paper with an attachment containing a rejection letter suggesting that the paper is the sort of thing that brings the profession into
} 
may again be made with books, where the criticism comes after publication in the form of book reviews which, though usually signed, are much more public. ${ }^{27}$

Hence do not give up, unless a clear problem has been identified that cannot be rectified; this is rarely the reason for rejection. It is again useful to seek advice from an experienced colleague, who may be able to read 'between the lines' and suggest useful directions and priorities. Nevertheless, before sending it to another journal, keep in mind that the paper may need substantial revisions, involving a large amount of work. Never simply make further copies and submit an unchanged paper to another journal.

Above all, do not argue with or complain to the editor, even if the referees are wrong. In some cases, the referees may be positive about the paper, but it is still rejected by the editor for reasons that are far from clear. Again, there is no point engaging in any kind of correspondence with the editor. This point holds even when the referees' reports are instantly recognised as 'hatchet jobs'. ${ }^{28}$

Although it may be hard to deal with a rejection at the time, it is worth keeping in mind that much can often be learned from negative reports, and even those where the referee makes incorrect statements. These reports, if studied dispassionately, provide clues to help avoid future misinterpretations. They can show where assumptions have not been stated clearly or justified sufficiently, or even where the aims or implications of the work have not been expressed clearly. Often, rejection is a matter of the weight given to certain objections or qualifications, and the paper may not have argued convincingly where those qualifications may not affect the main results.

Common reasons for rejection are that the paper is not well-motivated and its aims are not clear. This emphasises the need to pay special attention to the introduction, which often needs to be the most-rewritten part of any paper.

\footnotetext{
disrepute.

${ }^{27}$ Publishers may feel that there is no such thing as a bad review, but few authors would agree. It is worth remembering that reviewers often do not actually read books. The nineteenth century critic Sydney Smith once famously remarked, 'I never read a book before reviewing it; it prejudices a man so.'

${ }^{28}$ This is a very short report designed only to give an excuse for rejecting a paper. Here the referee will pick on anything (most likely not the most vulnerable points of the paper), and say things like 'this is well known' and make other unsubstantiated and often incorrect comments.
} 
Another frequent reason for rejection is that the contribution of the paper is simply not sufficient to warrant publication, which may be an indication that it needs to be sent to a journal where it will face less competition, though even then it may first need more work.

\subsection{Revise and Resubmit}

An invitation to revise and resubmit is usually the best that can be expected. However, do not expect the editor to make complimentary remarks, or even appear to encourage resubmission. The wording is usually something like, 'we would be willing to consider a revision along the lines suggested by referees' ${ }^{29}$ Editors and referees can sometimes be so opaque that a more experienced colleague may be needed to interpret the letter. Do not hesitate to show such letters to someone whose views you value. Such colleagues do not resent the time spent, and are simply passing on the type of advice from which they once benefited.

Do not expect referees to say kind things. In economics, even those who may like, or even admire, a paper feel obliged to concentrate on qualifications or other negative aspects. Nevertheless, the fact that a paper has not been rejected indicates at least a degree of sympathy on the part of the referees. Just a little bit of sympathy goes a long way and should be appreciated. Some inexperienced authors may feel discouraged by comments, when in fact they are relatively positive. After fist reading the reports, it can be helpful to set them aside for a day or so before returning to them in a less sensitive frame of mind.

After receiving a 'revise and resubmit' letter, do not delay making revisions. It may often be difficult to return to a problem that is no longer fresh in the mind, and when new work appears more attractive: but revisions should be given priority. ${ }^{30}$ Deal with all the points made by the editor and referees. The

\footnotetext{
${ }^{29}$ When finally accepting papers, most editors use the rather bland, 'your paper is now acceptable for publication'. Most editors seem congenitally unable to use the words 'sorry' or 'pleased'.

${ }^{30}$ One non-trivial reason for avoiding delays is that the editor may change and the replacement may be less sympathetic and have different views about the directions of the journal. Returning to work on an older paper is made easier if decent records are kept, regarding for example computer programs written, data used or derivations of analytical results.
} 
editor's letter may indicate which points made by the referees are considered to be the most important, or which referee carries more weight. It is usually helpful to start by dealing with the most critical comments, as these lead to the most substantive changes, so that the minor comments may be dealt with 'along with way'. The revision process is likely to require several iterations to ensure that all points are covered.

Perhaps the most common requirement stipulated by an editor is to cut material - do not ignore this. Sometimes it is necessary to cut diagrams, blocks of material or a section of the paper: this is quite easy, though it may be a little painful at first. More often a section needs to be shortened generally. The important point to realise is that compression - reducing unecessary words and repetition - can usually be achieved while at the same time improving the flow and clarity of the paper.

Do not simply make the minimum changes demanded. Take the opportunity to look closely at the whole of the paper, even if referees do not ask for many changes, to see if the clarity of the argument can be improved. The time interval involved has the effect of placing a greater distance between the paper and the author, allowing for the important element of self-criticism. Authors need to take the attitude that a paper can always be improved. Indeed, the revision process often leads the author to gain a much better understanding of the strengths and weaknesses of the paper, and a realisation of its real contribution, thereby improving the focus and motivation.

When resubmitting the paper, carefully explain the modifications in a covering letter to the editor. The explanation should deal with each of the points made by referees, and if they are not numbered it is useful to add numbers to the paragraphs for easy reference. Do not simply state that a change has been made, but refer explicitly to the part of the paper where the revision occurs. If you believe that a point made by a referee is wrong or misplaced, give clear and politely expressed reasons. Remember that the most common explanation for a wrong interpretation is that the paper was not actually clear. Sometimes referees differ about specific details and the editor does not indicate which one should be 
followed. In these cases, indicate the conflict and carefully explain the reasons for your choice. It is worth putting a draft letter aside for a couple of days: when returning to it, signs of irritation or an unpleasant tone may be clearer and thus expurgated.

Above all, do not assume that a revision, even where it seems that all points have been fully dealt with, will be accepted for publication. Keep in mind that the revision, along with the explanation to the editor, is likely to be returned to the original referees. More revisions may need to be made after further long delays and, even then, it is possible for papers to be rejected after going through several iterations. Some editors have a reputation for being less decisive than others.

\section{The Production Process}

An acceptance by the editor is by no means the end of the publication process. In economics, a further 18 months or two years often passes before the paper appears in print. During most of that time, the paper is simply waiting in a queue, but from the author's point of view the two important aspects are the contribution of sub-editors and the need to deal with proofs. These are discussed in turn in this section.

\section{$5.1 \quad$ Sub-editors}

An accepted paper is first sent to a sub-editor whose job is to ensure that it conforms with the journal's house style. ${ }^{31}$ Furthermore, checks are made to make sure, for example, that it has correct spelling and grammar, is consistent in its use of terms, and has all the bibliographical details needed. This process may give rise to 'author's queries', which may be dealt with by separate communication between the production department and the author, or they may be included with the page proofs.

\footnotetext{
${ }^{31}$ The sub-editor will also 'mark up' the material for the person responsible for layouts. Of course, modern production methods do not require typesetting, or extensive retyping.
} 
The extent of sub-editing of journal papers is usually 'light' and unobtrusive. ${ }^{32}$ A good sub-editor can make a valuable contribution in eliminating any ambiguities and making sure that the references to table numbers or sections of a paper are the correct ones. Sub-editors may suggest improvements to the headings and layout of tables which improve their transparency. It is horrifying to realise the extent to which authors can introduce minor, but potentially confusing, differences between numbers mentioned in the text of a paper and a table. Good sub-editors are perhaps undervalued by authors and journal editors alike, who often remain ignorant of the many details that need to be considered if the journal is to retain a consistent style and quality.

\subsection{Proofs}

The final task of the author is to check the page proofs. Fortunately, the quality of proofs has generally improved with the use of digital forms of printing, which has eliminated the need to retype most of the material. However, there are many opportunities to introduce errors, particularly in mathematical notation. Keep in mind that this is the last chance to correct errors before publication, but do not be tempted to introduce author's changes. These may not be accepted anyway, and can disrupt the carefully prepared page layout, as well as causing further errors to be introduced. However, take the opportunity to revise the bibliography where papers which were initially listed as 'forthcoming' have subsequently appeared in print. When checking proofs, read the paper several times. First, read it from front to end in the normal way. Then it is helpful to go through it in different directions: reading backwards places the emphasis on each word and avoids the usual problem of allowing the meaning of a sentence to lead to slight errors being missed.

\footnotetext{
${ }^{32}$ The process is sometimes more intrusive with books. Given the difficulty of dealing with a large manuscript with multiple chapters and many references, inconsistencies are more easily introduced. Some sub-editors can appear to be authors manqué, and it is necessary to watch for changes in meaning introduced by a small rewording.
} 


\section{Conclusions}

The aim of this paper has been to give a short description of the nature of books and journals, and their respective editors, and the difficult process and proprieties involved in publishing economics papers. Emphasis was given to the need to deal with rejections and the often substantial revisions requested by editors. While it is suggested that the peer review, or refereeing, process generally provides a useful 'filter' and does lead to improvements being made to papers, it is by no means perfect. ${ }^{33}$ Many authors have little difficulty recalling papers which have been made almost incomprehensible by imposed cuts or have had useful material deleted. There is a substantial element of luck, which means that all journals contain a mixture of qualities. Even those journals with a high average standard have a high dispersion, as well as rejecting papers which, after being published elsewhere, are eventually regarded as making important contributions. Almost all casual discussions among economists eventually turn to the subject of their recent treatment by journal editors and referees. Colleagues listen with sympathy to terrible stories of injustice, knowing that etiquette requires that their own stories will receive a captive audience. The sympathetic editor and constructive anonymous referee whose suggestions made substantial improvements to a paper, or saved the author from embarrassing errors, is rarely mentioned in such exchanges.

After several years of experience, economists typically have several papers in different stages, and eventually learn how to handle criticism and move on to the next paper or revision, without too much damage being done by a rejection, or too much stress being placed on an acceptance. After all, even authors, following a few early shocks, learn to recognise that they are perhaps not always necessarily the best judges of their own papers. Some papers actually turn out to be more valuable than their authors initially thought.

\footnotetext{
${ }^{33}$ For a survey of authors' views, see Leband (1990).
} 


\section{References}

[1] Creedy, J. (2001) Starting research. Australian Economic Review, 34, pp. $116-124$.

[2] Creedy, J. (2002) Entreprendre un travail de recherche et rédiger un papier de recherche. International Labour Office, ELIFID Working Paper, no. 02-1.

[3] Fischer, C. C. and Lawrence, J. E. (1997) Writing for economics journals: strategic elements. Journal of Economics, 23, pp. 31-45.

[4] Gans, J. S. (2000) Publishing Economics. Cheltenham: Edward Elgar.

[5] Gans, J. S. and Shephard, G. B. (1994) How are the mighty fallen: rejected classic articles by leading economists. Journal of Economic Perspectives, 8, pp. 165-179.

[6] Goffe, W. L. and Parks, R. P. (1997) The future information infrastructure in economics. Journal of Economic Perspectives, 11, pp. 75-94.

[7] Hamermesh, D. S. (1992) The young economist's guide to professional etiquette. Journal of Economic Perspectives, 6, pp. 169-179.

[8] Hamermesh, D. S. (1994) Facts and myths about refereeing. Journal of Economic Perspectives, 8, pp. 153-163.

[9] Huggett, R. (1986) The Wit of Publishing. London: W. H. Allen.

[10] Leband, D. N. (1990) Is there value-added from the review process in economics?: preliminary evidence from authors. Quarterly Journal of Economics, 103, pp. 341-352.

[11] Nowell-Smith, S. (1967) Letters to Macmillan. London: Macmillan.

[12] Roberts, S. C. (1966) Adventures With Authors. Cambridge: Cambridge University Press. 
[13] Shepherd, G. B. (ed) (1995) Rejected: Leading Economists Ponder the Publication Process. Sun Lakes, AZ: Horton.

[14] Unwin, (1926) The Truth About Publishing. London: Allen and Unwin.

[15] Unwin, (1960) The Truth About a Publisher. London: Allen and Unwin.

[16] Wheelock, J. H. (1950) Editor to Author: The Letters of Maxwell E. Perkins. New York: Scribners. 